\title{
Report on the proceedings of the International Symposium on Genitourinary Trichomoniasis, Paris 1977
}

An International Symposium on Genitourinary Trichomoniasis was held at the Institut Alfred Fournier in Paris on the 8 and 9 July. The meeting was held under the patronage of the Minister of Health of France, the World Health Organisation, and the International Union against the Venereal Diseases and Treponematoses. It was also supported by the French Society of Dermatology, the French Society of Gynaecology, and the Medical Society of Paris. The joint Presidents were Professor A. Netter and Doctor André Siboulet of France; the Organising Committee included Professor J. de Brux of France, Dr R. D. Catterall of the United Kingdom, Professor D. Panaitescu of Romania, and Professor Axel Perdrup of Denmark. The general secretary was Mr M. A. Fari. There were over 120 participants from a wide variety of countries.

Dr H. Morton-Nielsen of Denmark described the up-to-date electron microscopical appearance of Trichomonas vaginalis and outlined current ideas on the cell functions which could be related to pathogenic mechanisms. Dr M. Muller of New York gave a detailed account of the metabolism of trichomonads and its relationship to the chemotherapy of trichomoniasis. Abnormal forms of trichomonas were shown on slides and film by Dr J. John of England and the histochemical and ultrastructural aspects of the organism were discussed by $\mathrm{Dr} \mathrm{De}$ Carnieri of Italy. Round forms of $T$. vaginalis were described by $\mathrm{Dr} R$. Trevoux of France and these became the main subject of discussions throughout the symposium. Some speakers thought they could be artefacts and were not to be related to $T$. vaginalis, others thought that they were dying cells and therefore of little significance, but some felt that they represented a stage in the cycle of development of the organisms and were of patho- logical significance. There was considerable discussion on whether vaginal trichomoniasis should be diagnosed from the finding of round forms alone as no observer had seen these develop into classical forms of $T$. vaginalis.

The role of colposcopy in the diagnosis and management of patients with trichomoniasis was discussed by Dr R. Cartier, Dr R. Dajoux, and Professor J. Debrux. Their talks were illustrated by excellent colour slides. Dr T. Timon-David described the various types of trichomonads infesting the genital tract of mammals and Mr A. Fari gave a detailed description of laboratory methods of diagnosis currently in use in France. Dr F. Catalan compared the various diagnostic methods used in detecting trichomonas and Dr R. Blanc discussed the methods available for demonstrating round forms of trichomads in detail and showed many illustrations of them.

Professor J. Debrux described a series of patients in whom he had found cervical dysplasia associated with $T$. vaginalis and discussed the pathological changes and effects of treatment. Dr P. Timon-David gave an original paper on the consequences of infestation with trichomonas on sexual activity and considered the erotic effects of such infestations in women.

Genitourinary infections in men were described in detail by Dr J. Verges, a urologist with special experience in the subject. He discussed the incidence of asymptomatic infestations and methods of diagnosis in men.

Professor W. H. R. Lumsden outlined recent work on systemic and local immunity and said that it was unlikely that immunological techniques would lead to a satisfactory diagnostic test, especially for men.

Papers on the epidemiological aspects included a description of a study into the incidence of trichomoniasis among gynaecological patients in Haute-Volte, Africa $\stackrel{\varnothing}{\varrho}$ by Dr A. Rethel-Laurentin and another on the incidence of the condition at the whaling station in north Canada by Dr R. $\overrightarrow{0}$ Morisset. There were also papers on the $\overrightarrow{\vec{A}}$ same subject by $\operatorname{Dr} R$. Pradinaud from $\omega$ Guyana and from Dr A. Siboulet of $\omega$ France.

There were many papers describing $\omega$ treatment, most of which reported the cure rates after treatment with a variety of imidazole preparations. By adding a selection of side chains to the basic 을 molecule, new preparations have been $\rightarrow$ produced with a bewildering variety of $\square$ trade names. It was apparent that the systemic treatment of infested patients was satisfactory and the failure rate was low.

Dr Muller of New York described the $\vec{\varphi}$ mode of action of metronidazole of $\mathcal{V}$ trichomonads and anaerobic organisms He was of the opinion that all the avai able imidazole preparations were poten+ tially mutogenic and it seemed reasonable $\bar{\partial}$ to recommend that the dosage be kept as low as possible and the duration of $\frac{2}{D}$ treatment short. Imidazole preparations were probably better not given during the first trimester of pregnancy.

The chief topics throughout the symposium were the so-called round forms of trichomonas and whether they were os really part of the life-cycle of the parasite or merely artefacts; the important question was, were the imidazole preparations really mutogenic and were they in any way dangerous to patients in the dosage normally employed?

The symposium ended with a vote of thanks to Dr Siboulet, Professor Netter, 음 and the organisers. The social programme included a reception at the $N$ Institut Alfred Fournier and a dinnershow at the Lido in the Avenue des Champs-Élysées. 